\title{
Synthesis and Structural Determination of Two New tri-Heterocyclic Regioisomeric Compounds, Precursors of Bi-Triazolic $\alpha$-Amino Acids, via a Comparative Study using 1D NMR Spectroscopy
}

\author{
S. Hajib, A. Ksakas, Y. Aouine, A. Alami, and H. Faraj
}

\section{ABSTRACT}

In this article, we describe the synthesis of two new triheterocyclic regioisomers, named 4-(\{4-[(1H-1,2,4-triazol-1-yl)methyl]-1H-1,2,3-triazol1-yl $\}$ methyl)-4-ethyl-2-phenyl-4,5-dihydrooxazole and 4-(\{5-[(1H-1,2,4triazol-1-yl)methyl]-1H-1,2,3-triazol-1-yl\}methyl)-4-ethyl-2-phenyl-4,5dihydrooxazole. The action of 1-(propargyl)-1H-1,2,4-triazole on 4(azidomethyl)-4-ethyl-2-phenyl-4,5-dihydrooxazole, in a very small quantity of toluene, led after 48 hours at $120{ }^{\circ} \mathrm{C}$ to two regioisomers with an overall yield of $90 \%$. The allocation of structures to these two regioisomers was carried out based on a comparative spectroscopic study using 1D NMR of the proton and carbon 13, as well as based on data from the literature concerning the cycloaddition reaction.

Keywords: Azide, 1,3-dipolar cycloaddition, 1D NMR spectroscopic study, oxazoline derivatives, 1,4-regioisomer, 1,5-regioisomer, 1,2,3triazole, 1,2,4-triazole.
Published Online: December 22, 2020

ISSN: $2684-4478$

DOI : $10.24018 /$ ejchem.2020.1.6.36

\section{S. Hajib}

Engineering Laboratory of Organometallic, Molecular Materials and Environment (LIMOME), Faculty of Sciences Dhar El Mahraz, Sidi Mohammed Ben Abdellah University, Morocco.

(e-mail: hajib.sarah@gmail.com)

A. Ksakas

Materials, Processes, Catalysis and Environment Laboratory, Morocco.

(e-mail: adilksakas@gmail.com)

Y. Aouine

Team of Organic Chemistry and Valorization of Natural Substances (COVSN), Faculty of Sciences, Ibn Zohr University, Morocco.

(e-mail: y.aouine@uiz.ac.ma)

A. Alami *

Engineering Laboratory of

Organometallic, Molecular Materials and Environment (LIMOME), Faculty of Sciences Dhar El Mahraz, Sidi Mohammed Ben Abdellah University, Morocco.

(e-mail: anouar.alami@usmba.ac.ma) H. Faraj

Engineering Laboratory of Organometallic, Molecular Materials and Environment (LIMOME), Faculty of Sciences Dhar El Mahraz, Sidi Mohammed Ben Abdellah University, Morocco.

(e-mail: hassanefaraj ${ }^{\circledR}$ yahoo.fr)

*Corresponding Author

\section{INTRODUCTION}

Heterocycles are recurrent motifs that can be found in many families of natural products, as well as in many biologically active molecules for pharmaceutical or agrochemical uses. The study of five-membered heterocyclic systems has undergone considerable development due to the discovery of their biological activities. Triazoles are an important class of these biologically active compounds. Various compounds with one or more triazole ring have a broad spectrum of activities such as antibacterial [1], antiproliferative agents [1], [2], antifungal compounds [3], anticancer and anti-diabetic properties [4], [5], and are also used as corrosion inhibitors [6].

In recent years, the synthesis of triazolic derivatives has undergone significant development. Since Huisgen's work in 
1963 [7] the most developed method for the synthesis of 1,2,3-triazoles derivatives is the 1,3-dipolar cycloaddition reaction. The synthesis of 1,2,3-triazole derivatives by this reaction has seen a remarkable evolution [8]-[11]. This 1,3dipolar cycloaddition reaction between azides and acetylenic dipolarophiles leads to two regioisomers $(1,4)$ and $(1,5)$, whose proportions vary according to the nature of the azide, the dipolarophile and the operating conditions. In view of these observations and in continuity with our previous work on the synthesis of heterocyclic amino acid derivatives and their precursors [12]-[20], we have synthesized two new oxazolinic compounds with excellent yield, precursors of bitriazolic amino acids via a 1,3-dipolar cycloaddition reaction between 4-(azidomethyl)-4-ethyl-2-phenyl-4,5dihydrooxazole 2 and 1-(prop-2-yn-1-yl)-1H-1,2,4-triazole 3. The structure of the two regioisomeric derivatives was attributed by means of a 1D NMR spectroscopic study of proton and carbon 13, as well as on the basis of literature data on the cycloaddition reaction.

\section{RESULTS AND DISCUSSION}

The starting compound, (4-methyl-2-phenyl-4,5dihydrooxazol4-yl)methyl-4-methylbenzenesulfonate 1 was prepared in two steps with an overall yield of $85 \%$ from the commercial product 2-amino-2-methyl propan-1,3-diol (CAS No. [115-69-5]) according to the method used by El Hajji et al. [12]. The action of sodium azide on the tosylated product in DMF at $120^{\circ} \mathrm{C}$ for 48 hours gives the dipole azide 2 with a yield of $80 \%$ in the form of a colorless oil.

The alkyne 1-(prop-2-yn-1-yl)-1H-1,2,4-triazole 3 (CAS No. [82418-39-1]) used as dipolarophile, has been resynthesized according to the approach described in the literature [21], by nucleophilic substitution between propargyl bromide (CAS No. [106-96-7]) and 1H-1,2,4triazole (CAS No. [288-88-0]) in DMF at room temperature in the presence of $\mathrm{K}_{2} \mathrm{CO}_{3}$ as base and tetrabutylammonium bromide BTBA as phase transfer catalyst. Thus, this protocol allowed to obtain and characterize the alkyne derived from $1 H$-1,2,4-triazole 3 with a yield of $90 \%$.

The 1,3-dipolar cycloaddition reaction is carried out by condensation of dipolarophile $\mathbf{3}$ and dipole azide $\mathbf{2}$ after 48 hours of heating at $120^{\circ} \mathrm{C}$ in the minimum of toluene, leading to two 1,4- and 1,5- regioisomers with a good yield (Scheme $1)$.

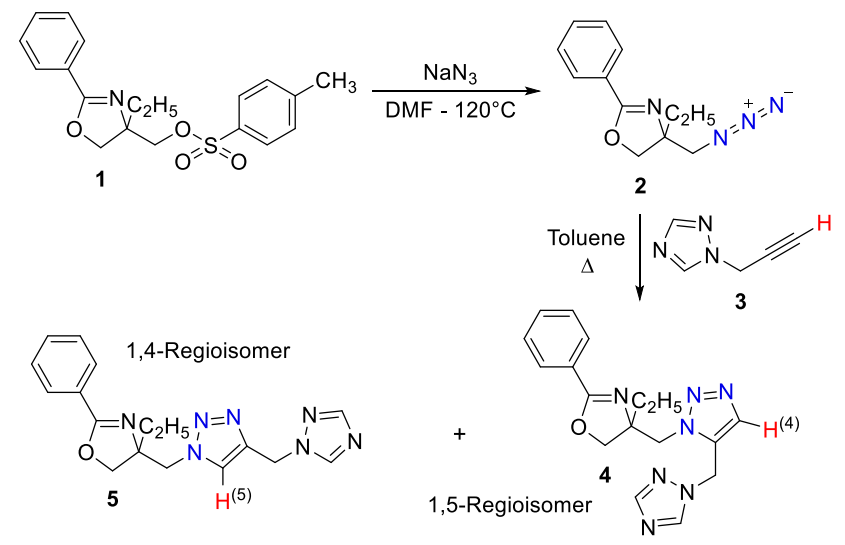

Scheme. 1. Synthetic route of bitriazolic amino acids precursors.
Intermediate $\mathbf{2}$ was purified by chromatography on a silica gel column (eluent: ether/hexane: 1/4), and it was characterized for the first time by 2D NMR (Fig. 1). The definite assignment of the chemical shifts of protons and carbons are shown in Table 1 . The ${ }^{1} \mathrm{H}$ NMR spectrum shows two $\mathrm{AB}$ systems around 3.28-3.58 and 4.16-4.32 ppm corresponding respectively to the 4 protons of the two methylene groups $-\mathrm{CH}_{2}-\mathrm{N}_{3}$ and $-\mathrm{CH}_{2}-(\mathrm{Oxaz})$ and with coupling constants $J=12.3 \mathrm{~Hz}$ and $J=8.7 \mathrm{~Hz}$.

TABLE I: NMR SPECTRAL DATA FOR COMPOUND 2

\begin{tabular}{|c|c|c|c|c|}
\hline Position & ${ }^{(* *)} \delta_{\mathrm{H}}$ & ${ }^{(* *)} \delta_{\mathrm{C}}$ & $\begin{array}{c}{ }^{\left({ }^{*}\right)} \text { Correlation } \\
\mathrm{H}-\mathrm{H}\end{array}$ & $\begin{array}{c}{ }^{(*)} \text { Correlation } \\
\mathrm{C}-\mathrm{H}\end{array}$ \\
\hline 1 & $\begin{array}{c}0.94 \\
(\mathrm{t}, J=7.4)\end{array}$ & 7.75 & $\begin{array}{l}3 \mathrm{H}^{1}-3 \mathrm{H}^{1} \\
3 \mathrm{H}^{1}-2 \mathrm{H}^{2}\end{array}$ & $\mathrm{C}^{1}-3 \mathrm{H}^{1}$ \\
\hline 2 & $1.61-1.85(\mathrm{~m})$ & 29.88 & $\begin{array}{l}2 \mathrm{H}^{2}-2 \mathrm{H}^{2} \\
2 \mathrm{H}^{2}-3 \mathrm{H}^{1}\end{array}$ & $\mathrm{C}^{2}-2 \mathrm{H}^{2}$ \\
\hline 3 & - & 74.18 & - & - \\
\hline 4 & $\begin{array}{c}3.3-3.6(\mathrm{AB} \\
J=12.3)\end{array}$ & 58.15 & $2 \mathrm{H}^{4}-2 \mathrm{H}^{4}$ & $\mathrm{C}^{4}-2 \mathrm{H}^{4}$ \\
\hline 5 & $\begin{array}{c}4.16-4.32 \\
(\mathrm{AB}, J=8.7)\end{array}$ & 72.80 & $2 \mathrm{H}^{5}-2 \mathrm{H}^{5}$ & $\mathrm{C}^{5}-2 \mathrm{H}^{5}$ \\
\hline 6 & - & 164.26 & - & - \\
\hline $7-12$ & 7.39-7.99 (m) & $\begin{array}{c}127.39- \\
131.58\end{array}$ & $5 \mathrm{H}_{\text {arom }}-5 \mathrm{H}_{\text {arom }}$ & $5 \mathrm{C}_{\text {arom }}-5 \mathrm{H}_{\text {arom }}$ \\
\hline
\end{tabular}

(*) Including results obtained by homonuclear 2D shift-correlated and heteronuclear 2D shift-correlated HMBC.

(**) Chemical shifts ( $\delta$ in ppm) and coupling constants $(\mathrm{J}$ in $\mathrm{Hz})$.

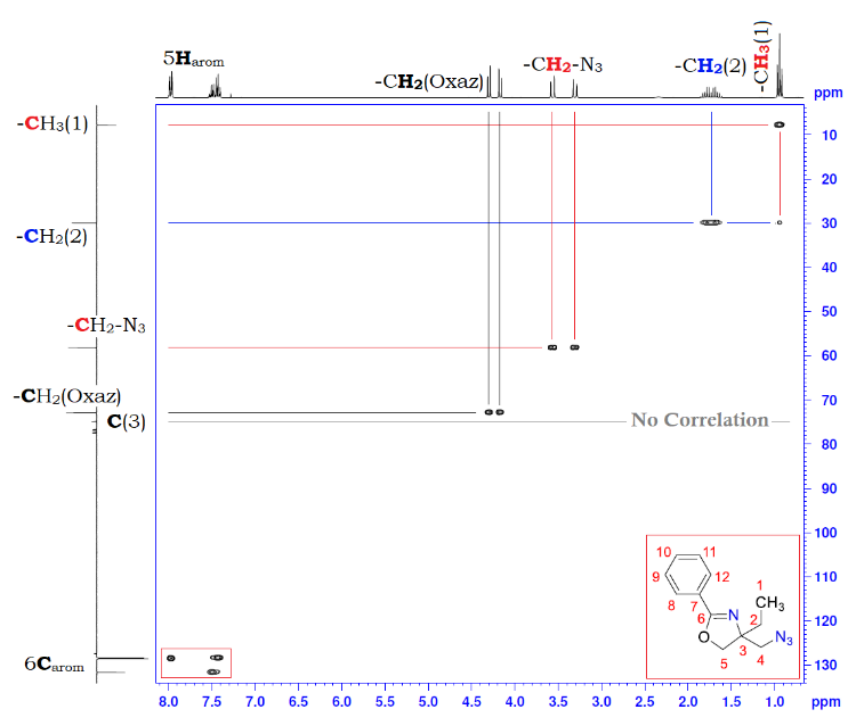

Fig. $1 .{ }^{1} \mathrm{H}^{13} \mathrm{C}$ Heteronuclear 2D spectrum (in $\mathrm{CDCl}_{3}$ ) of compound 2.

According to the data in the literature and the results obtained by the different members of our team [12], [13], [22]-[24], the cyclocondensation of alkynes on azides leads to two regioisomers in different proportions with a preponderance of the 1,4-regioisomer. The attribution of structures to the isomeric triazoles was essentially based on the ${ }^{1} \mathrm{H}$ and ${ }^{13} \mathrm{C}$ NMR spectroscopic studies [25], [26].

The separation of the reaction crude from this cyclocondensation, by silica gel column chromatography (eluent: ethyl acetate) allowed us to isolate these two regioisomers with an overall yield of $90 \%$. 


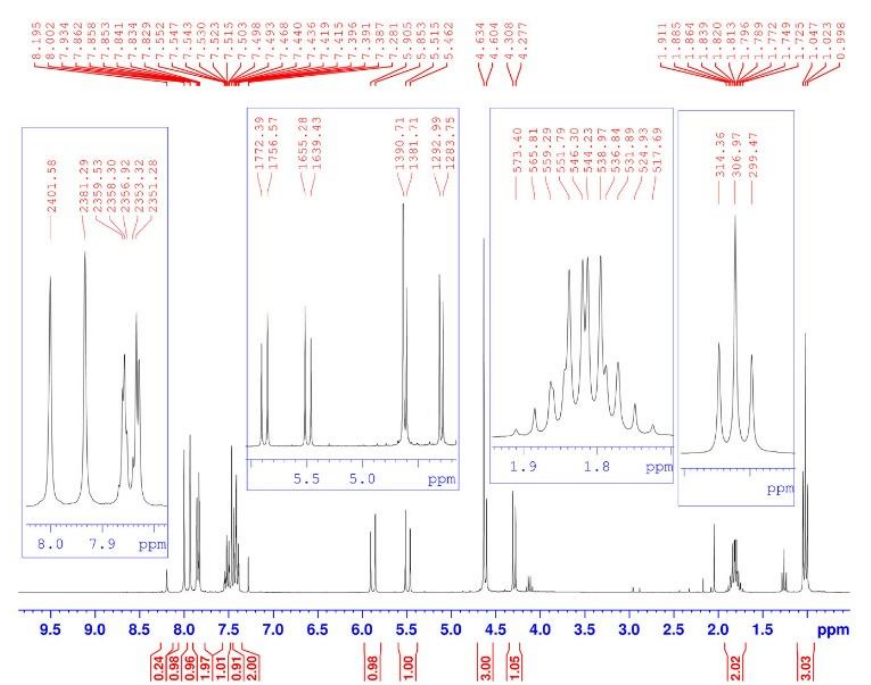

Fig. 2. ${ }^{1} \mathrm{H}$ RMN spectrum of 1,5-regioisomer 4.

The ${ }^{1} \mathrm{H}$ NMR spectrum of the minority regioisomer 4 , eluted in first, was characterized by the presence of two $\mathrm{AB}$ systems at 4.27-4.63 and 5.46-5.90 ppm corresponding successively to the protons of the two methylenes $-\mathrm{CH}_{2}$ (Oxaz) and $-\mathrm{CH}_{2}-(1,2,3$-triaz) and also by the presence of a singlet at 7,47 ppm assigned to the $\mathrm{H}(4)$ proton of the 1,2,3triazole nucleus (Fig. 2).

The analysis of the ${ }^{13} \mathrm{C}$-NMR spectrum of compound $\mathbf{4}$ shows (Fig. 3), the presence of two signals around 132.64 and $134.03 \mathrm{ppm}$ characteristic at the quaternary and tertiary carbons of the 1,2,3-triazole ring.

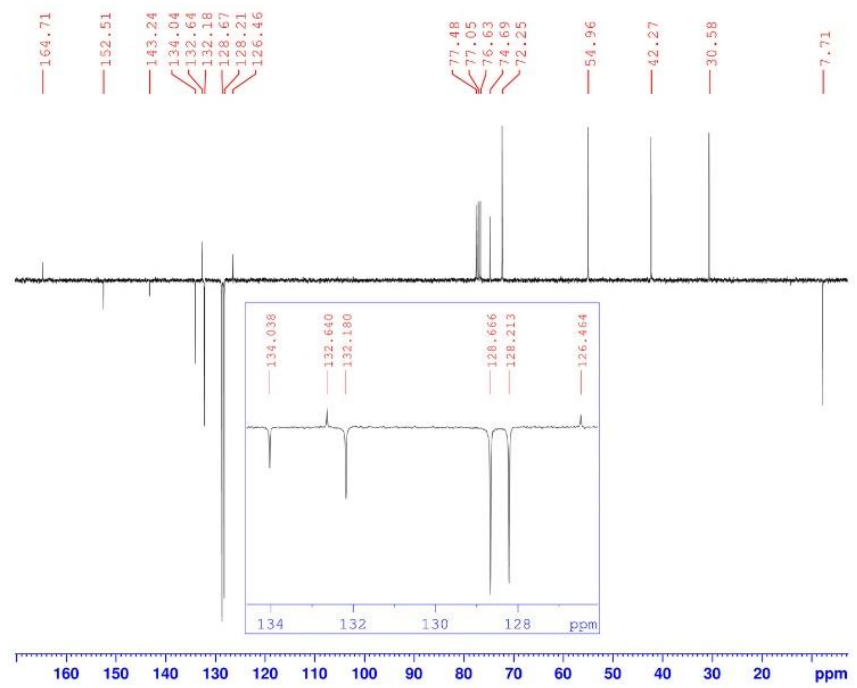

Fig. 3. ${ }^{13} \mathrm{C}$ RMN spectrum of 1,5-regioisomer 4 .

The ${ }^{1} \mathrm{H}$ NMR spectrum of the majority regioisomer $\mathbf{5}$, eluted in second, was also characterized by the presence of two $\mathrm{AB}$ systems at 4.18-4.33 and 4.48-4.62 ppm corresponding successively to the protons of the two methylenes - $\mathrm{CH}_{2}-(\mathrm{Oxaz})$ and $-\mathrm{CH}_{2}-(1,2,3-$ triaz $)$, and a singulet at $7.98 \mathrm{ppm}$ characteristic of the proton $\mathrm{H}(5)$ of the 1,2,3-triazole nucleus (Fig. 4).

As for its ${ }^{13} \mathrm{C}$ NMR spectrum, it revealed, among others, two signals corresponding to the carbon, quaternary, and tertiary of the 1,2,3-triazole ring, successively around 141.48 and 124.70 ppm (Fig. 5).

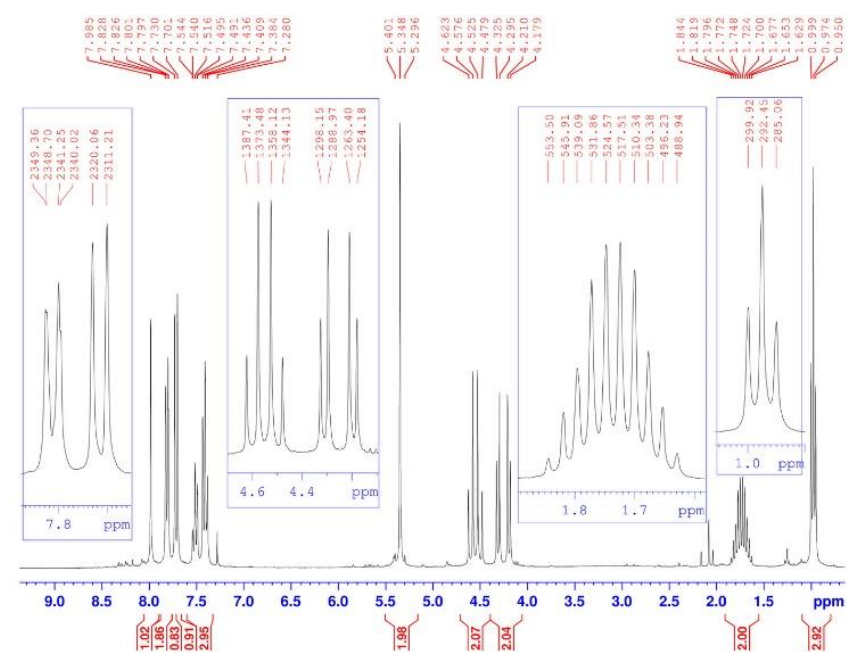

Fig. 4. ${ }^{1} \mathrm{H}$ RMN spectrum of 1,4-regioisomer 5.

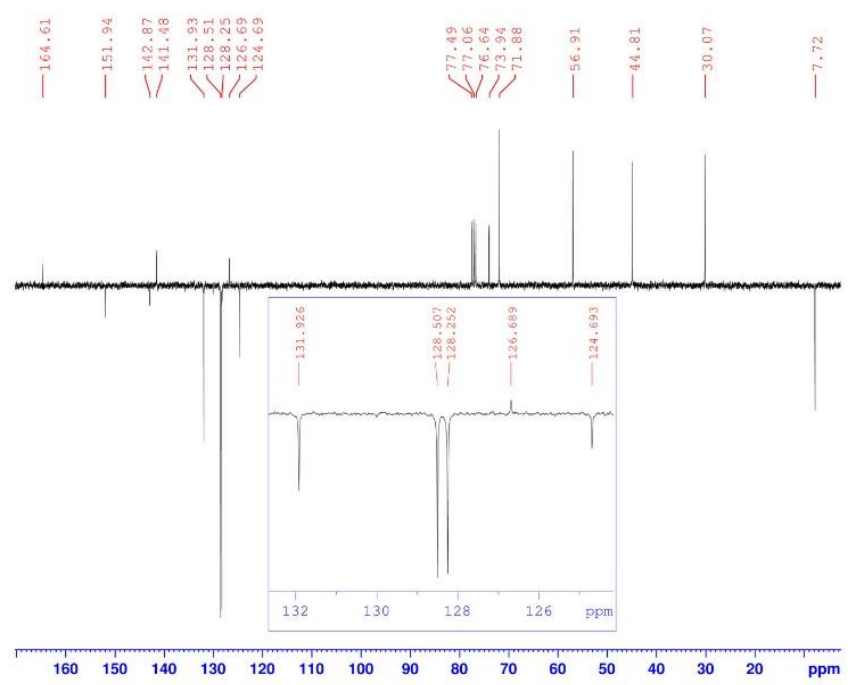

Fig. 5. ${ }^{13} \mathrm{C}$ RMN spectrum of 1,4-regioisomer 5 .

A comparative study of the ${ }^{1} \mathrm{H}$ NMR spectra at $300 \mathrm{MHz}$ of the two regioisomers shows that the two protons of the methylene group located between the two triazole cycles are present in both regioisomers in the form of a deshielded singlet in the case of the majority regioisomer $5(\delta \sim 5.35$ $\mathrm{ppm})$ than in the case of the minority regioisomer $4(\delta \sim 4.63$ ppm) (Fig. 2 and 4). In addition, the methylene protons located between the 1,2,3-triazole nucleus and the oxazolinic nucleus are more widely separated and deshielded in the minority regioisomer $\mathbf{4}$ than in the majority regioisomer $\mathbf{5}$ (Fig. 2 and 4).

The same is true for the protons of the methylene of the oxazolinic group, which shows that the three methylene groups do not have the same environment. This is probably due to the hindrance of the 1,2,4-triazole ring, which is located just below the rest of the molecule.

Similarly, a comparison of the ${ }^{13} \mathrm{C}$ NMR spectra of the two regioisomers shows that the tertiary carbon of the $1,2,3$ triazole ring in the minority regioisomer $\mathbf{4}$ is more deshielded $(134.03 \mathrm{ppm})$ than that of the tertiary carbon in the majority regioisomer 5 (124.70 ppm). This deshielding phenomenon is reversed in the case of the quaternary carbons of the 1,2,3triazole ring (132.64 ppm and $141.48 \mathrm{ppm})$. The difference between the chemical displacements is the same $(\delta \sim 9 \mathrm{ppm})$ 
for both tertiary and quaternary carbons. This difference is probably due to the relocation of electrons to the $\mathrm{C}(5)$ of the 1,2,3-triazole ring.

All these data allowed us to attribute the structure of 4-( $\{5$ [(1H-1,2,4-triazol-1-yl)methyl]-1H-1,2,3-triazol-1yl \}methyl)-4-ethyl-2-phenyl-4,5-dihydrooxazole to the minority regioisomer 4 and the structure of 4- $(\{4-[(1 H-1,2,4-$ triazol-1-yl)methyl]-1H-1,2,3-triazol-1-yl \}methyl)-4-ethyl2-phenyl-4,5-dihydrooxazole to the majority regioisomer $\mathbf{5}$
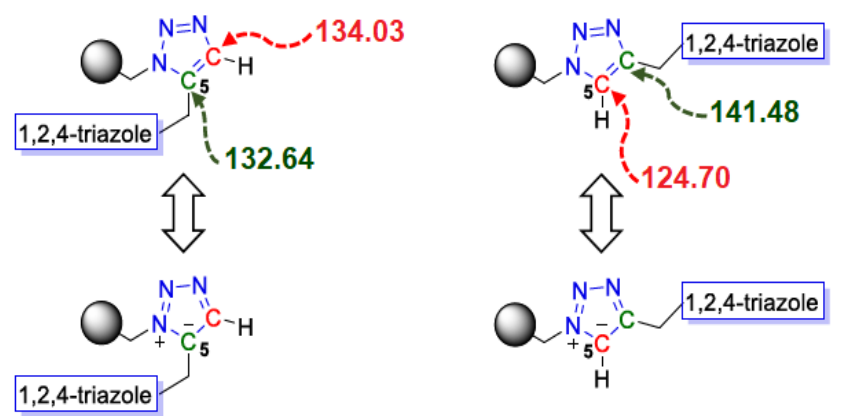

Fig. 6. Chemical shifts of tertiary $(\mathrm{Ct})$ and quaternary $(\mathrm{Cq})$ carbon atoms

\section{MATERIALS AND METHODS}

All solvents were purified following the standard techniques and commercial reagents were purchased from Sigma-Aldrich (St. Louis, MO, USA). Melting point was determined with an electrothermal melting point apparatus and was uncorrected. NMR spectra $\left({ }^{1} \mathrm{H}\right.$ and $\left.{ }^{13} \mathrm{C}\right)$ were recorded on a Bruker AM 300 spectrometer (operating at $300.13 \mathrm{MHz}$ for ${ }^{1} \mathrm{H}$, at $75.47 \mathrm{MHz}$ for ${ }^{13} \mathrm{C}$ ) (Bruker Analytische Messtechnik GmbH, Rheinstetten, Germany). NMR data are listed in ppm and are reported relative to tetramethylsilane $\left({ }^{1} \mathrm{H},{ }^{13} \mathrm{C}\right)$; residual solvent peaks being used as an internal standard. All reactions were followed by thinlayer chromatography (TLC). TLC analyses were carried out on $0.25 \mathrm{~mm}$ thick precoated silica gel plates (Merck Fertigplatten Kieselgel $60 \mathrm{~F}_{254}$ ) and spots were visualized under UV light or by exposure to vaporized iodine. Mass spectra were recorded on a PolarisQ Ion Trap GC/MSn Mass Spectrometer (CNRST-Rabat).

4-(azidomethyl)-4-ethyl-2-phenyl-4,5-dihydrooxazole 2. To a solution of 5.5 mmoles of starting product 1 in $60 \mathrm{~mL}$ of DMF, 27.5 mmoles of $\mathrm{NaN}_{3}$ were added in small portions and with stirring. The reaction mixture was then heated at a temperature of $120{ }^{\circ} \mathrm{C}$ for 48 hours while maintaining stirring. After stopping the reaction, the solution was reduced to half by distillation under reduced pressure, and then was extracted 3 times with ether $(3 \times 20 \mathrm{~mL})$. The resulting crude was purified by chromatography of silica gel column (eluent: ether/hexane: 10/90). Yield $=90 \%$ (Colorless oil); $\mathrm{Rf}=0.6$ (ether/hexane 1/1); ${ }^{1} \mathrm{H}-\mathrm{NMR}\left(\mathrm{CDCl}_{3}, \delta_{\mathrm{H}} \mathrm{ppm}\right): 0.94(3 \mathrm{H}, \mathrm{t},-$ $\left.\mathrm{CH}_{2}-\mathrm{CH}_{3},{ }^{3} \mathrm{~J}=7.4 \mathrm{~Hz}\right), 1,70\left(2 \mathrm{H}, \mathrm{m},-\mathrm{CH}_{2}-\mathrm{CH}_{3},{ }^{3} \mathrm{~J}=7.4 \mathrm{~Hz}\right)$, 3.29-3.58 (2H, AB, $\left.-\mathrm{CH}_{2}-\mathrm{N}_{3},{ }^{2} J=12.3 \mathrm{~Hz}\right), 4.16-4.32(2 \mathrm{H}$, $\left.\mathrm{AB},-\mathrm{CH}_{2}(\mathrm{Oxaz}),{ }^{2} J=8.7 \mathrm{~Hz}\right), 7.40-7.99\left(5 \mathrm{H}, \mathrm{m}, 5 \mathrm{H}_{\text {arom }}\right)$. ${ }^{13} \mathrm{C}-\mathrm{NMR}\left(\mathrm{CDCl}_{3}, \delta_{\mathrm{C}} \mathrm{ppm}\right): 7.75\left(1 \mathrm{C},-\mathrm{CH}_{2}-\mathrm{CH}_{3}\right), 29.88(1 \mathrm{C}$, $\left.-\mathrm{CH}_{2}-\mathrm{CH}_{3}\right), 58.15\left(1 \mathrm{C},-\mathrm{CH}_{2}-\mathrm{N}_{3}\right), 72.80\left(1 \mathrm{C},-\mathrm{CH}_{2}(\mathrm{Oxaz})\right)$, $74.81\left(1 \mathrm{C},-\mathrm{C}_{\mathrm{q}}(\mathrm{Oxaz})\right), 127.39,128.36,128.48,131.58$ (6C, $\left.6 \mathrm{C}_{\text {arom }}\right), 164.26(1 \mathrm{C}, \mathrm{CN})$.
1-(prop-2-yn-1-yl)-1H-1,2,4-triazole 3. To a stirred solution of 10 mmoles of $1 \mathrm{H}-1,2,4$-triazole in $30 \mathrm{~mL}$ of acetone, 15 mmoles of $\mathrm{K}_{2} \mathrm{CO}_{3}$ were added in small portions with a catalytic amount of tetrabutylammonium bromide. After about one hour, 10 mmoles of propargyl bromide were added. The mixture was stirred at room temperature for 16 hours. The solvent was evaporated and the residue was extracted with ether. The organic layer was dried with sodium sulfate $\left(\mathrm{Na}_{2} \mathrm{SO}_{4}\right)$ and the solvent was removed. Yield $=90 \%$ (White solid); m.p. $<40{ }^{\circ} \mathrm{C}$; $\mathrm{Rf}=0.45$ (ether); ${ }^{1} \mathrm{H}-\mathrm{NMR}$ $\left(\mathrm{CDCl}_{3}, \delta_{\mathrm{H}} \mathrm{ppm}\right): 2.8\left(1 \mathrm{H}, \mathrm{t},-\mathrm{C} \equiv \mathrm{C}-\mathrm{H},{ }^{4} \mathrm{~J}=3 \mathrm{~Hz}\right), 5.1(2 \mathrm{H}, \mathrm{d}$,

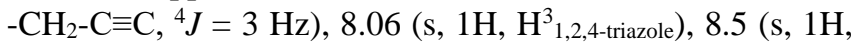
$\mathrm{H}^{5}$ 1,2,4-triazole).

1,3-Dipolar cycloaddition reaction. To a solution of 4.34 mmoles of product 2 in $4 \mathrm{~mL}$ of toluene, 4.67 mmoles of 1 (prop-2-yn-1-yl)-1H-1,2,4-triazole $\mathbf{3}$ were added. The resulting solution was kept under magnetic stirring and heating at $120{ }^{\circ} \mathrm{C}$ for 48 hours. After cooling to room temperature, the crude mixture was purified by chromatography of silica gel column (eluent: ethyl acetate).

4-(\{5-[(1H-1,2,4-triazol-1-yl)methyl]-1H-1,2,3-triazol-1yl\}methyl)-4-ethyl-2-phenyl-4,5-dihydrooxazole 4. Yield = $80 \%$ (Green oil); $\mathrm{Rf}=0.6$ (ethyl acetate/methanol 5\%); Diast ratio. $=30 \% ;{ }^{1} \mathrm{H}-\mathrm{NMR}\left(\mathrm{CDCl}_{3}, \delta_{\mathrm{H}} \mathrm{ppm}\right): 1.02\left(3 \mathrm{H}, \mathrm{t},-\mathrm{CH}_{2-}\right.$ $\left.\mathrm{CH}_{3},{ }^{3} \mathrm{~J}=7.5 \mathrm{~Hz}\right), 1,81\left(2 \mathrm{H}, \mathrm{m},-\mathrm{CH}_{2}-\mathrm{CH}_{3},{ }^{3} \mathrm{~J}=7.5 \mathrm{~Hz}\right), 4.28-$ $4.63\left(2 \mathrm{H}, \mathrm{AB},-\mathrm{CH}_{2}(\mathrm{Oxaz}),{ }^{2} \mathrm{~J}=9.3 \mathrm{~Hz}\right), 4.63\left(2 \mathrm{H}, \mathrm{s},-\mathrm{CH}_{2-}\right.$ (1,2,4-Triaz)), 5.46-5.91 (2H, AB, - $\mathrm{CH}_{2}-(1,2,3-$ Triaz $),{ }^{2} J=16$ $\mathrm{Hz}), 7.39-7.86\left(5 \mathrm{H}, \mathrm{m}, 5 \mathrm{H}_{\text {arom }}\right), 7.47$ (s, $\left.1 \mathrm{H}, \mathrm{H}^{4}{ }_{1,2,3 \text {-triazole }}\right), 7.93$ (s, $1 \mathrm{H}, \mathrm{H}^{3}{ }_{1,2,4 \text {-triazole }),} 8.00\left(\mathrm{~s}, 1 \mathrm{H}, \mathrm{H}^{5}{ }_{1,2,4 \text {-triazole }) .}{ }^{13} \mathrm{C}-\mathrm{NMR}\right.$ $\left(\mathrm{CDCl}_{3}, \delta_{\mathrm{C}} \mathrm{ppm}\right): 7.70\left(1 \mathrm{C},-\mathrm{CH}_{2}-\mathrm{CH}_{3}\right), 30.58\left(1 \mathrm{C},-\mathrm{CH}_{2}-\right.$ $\left.\mathrm{CH}_{3}\right), 42.24\left(1 \mathrm{C},-\mathrm{CH}_{2}-(1,2,4-\mathrm{Triaz})\right), 54.96\left(1 \mathrm{C},-\mathrm{CH}_{2}-\right.$ (1,2,3-Triaz)), 72.24 (1C, $\left.-\mathrm{CH}_{2}(\mathrm{Oxaz})\right), 74.69$ (1C, $\left.\mathrm{C}_{\mathrm{q}}(\mathrm{Oxaz})\right), 126.24,128.21,128.67,132.18$ (6C, 6C $\left.\mathrm{C}_{\text {arom }}\right)$,

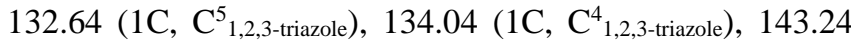
(1C, $\mathrm{C}^{3}$ 1,2,4-triazole), 152.51 (1C, $\mathrm{C}^{5} 1,2,4$-triazole $), 164.71(1 \mathrm{C}, \mathrm{CN})$. MS (EI): m/z (rel. int. \%) = $337(100 \%)(\mathrm{M}+)$.

4-(\{4-[(1H-1,2,4-triazol-1-yl)methyl]-1H-1,2,3-triazol-1yl)methyl)-4-ethyl-2-phenyl-4,5-dihydrooxazole 5. Yield = $80 \%$ (Yellow oil); $\mathrm{Rf}=0.37$ (ethyl acetate/methanol 5\%); Diast. ratio. $=70 \% ;{ }^{1} \mathrm{H}-\mathrm{NMR}\left(\mathrm{CDCl}_{3}, \delta_{\mathrm{H}} \mathrm{ppm}\right): 0.97(3 \mathrm{H}, \mathrm{t}$, $\left.-\mathrm{CH}_{2}-\mathrm{CH}_{3},{ }^{3} \mathrm{~J}=7.5 \mathrm{~Hz}\right), 1,72\left(2 \mathrm{H}, \mathrm{m},-\mathrm{CH}_{2}-\mathrm{CH}_{3},{ }^{3} \mathrm{~J}=7.5 \mathrm{~Hz}\right)$, 4.18-4.32 (2H, AB, $\left.-\mathrm{CH}_{2}(\mathrm{Oxaz}),{ }^{2} J=9.3 \mathrm{~Hz}\right), 4.48-4.62(2 \mathrm{H}$, $\left.\mathrm{AB},-\mathrm{CH}_{2}-(1,2,3-\mathrm{Triaz}),{ }^{2} \mathrm{~J}=14.1 \mathrm{~Hz}\right), 5.35\left(2 \mathrm{H}, \mathrm{s},-\mathrm{CH}_{2-}\right.$ (1,2,4-Triaz)), 7.38-7.82 (5H, m, 5 $\left.\mathrm{H}_{\text {arom }}\right), 7.71\left(\mathrm{~s}, 1 \mathrm{H}, \mathrm{H}^{3}{ }_{1,2,4}\right.$

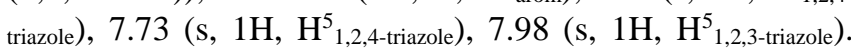
${ }^{13} \mathrm{C}-\mathrm{NMR}\left(\mathrm{CDCl}_{3}, \delta_{\mathrm{C}} \mathrm{ppm}\right): 7.72\left(1 \mathrm{C},-\mathrm{CH}_{2}-\mathrm{CH}_{3}\right), 30.07(1 \mathrm{C}$, $\left.-\mathrm{CH}_{2}-\mathrm{CH}_{3}\right), 44.81$ (1C, $-\mathrm{CH}_{2}-(1,2,4-$ Triaz $\left.)\right), 56.91\left(1 \mathrm{C},-\mathrm{CH}_{2}-\right.$ (1,2,3-Triaz)), 71.88 (1C, - $\left.\mathrm{CH}_{2}(\mathrm{Oxaz})\right), 73.94 \quad(1 \mathrm{C}$, $\left.\mathrm{C}_{\mathrm{q}}(\mathrm{Oxaz})\right), 124.70$ (1C, $\mathrm{C}^{5}$ 1,2,3-triazole $), 126.69,128.25,128.50$, 131.92 (6C, 6C $\left.\mathrm{C}_{\text {arom}}\right), 141.48$ (1C, $\left.\mathrm{C}^{4}{ }_{1,2,3 \text {-triazole }}\right), 142.87$ (1C,

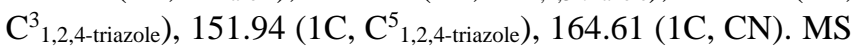
(EI): $\mathrm{m} / \mathrm{z}($ rel. int. \%) $=337(100 \%)(\mathrm{M}+)$.

\section{CONCLUSION}

In summary, this work describes the synthesis of new oxazolinic precursors of bitriazolic $\alpha$-amino acids as a new class of 1,2,3-triazole derivatives, in good yield (90\%) with easy work up. This new tri-bitriazolic sequence represents a 
set of potentially interesting compounds for biological and electrochemical activities screening and we believe that applications for them will be soon found in organic chemistry, medicinal chemistry, and electrochemistry.

\section{ACKNOWLEDGMENT}

This work was supported by Sidi Mohammed Ben Abdellah University (USMBA) and National Center for Scientific and Technical Research (CNRST).

\section{REFERENCES}

[1] G. Singh, J. Singh, A. Singh, J. Singh, M. Kumar, K. Gupta, S. Chhibber, "Synthesis, characterization and antibacterial studies of schiff based 1,2,3-triazole bridged silatranes," Journal of Organometallic Chemistry, vol. 871, pp. 21-27, 2018.

[2] S. Fusco, D. Capasso, R. Centore, S. Di Gaetano, E. Parisi, "A new biologically active molecular scaffold: crystal structure of 7-(3 hydroxyphenyl)-4-methyl-2 $\mathrm{H}$-[1,2,4]triazolo[3,2-c][1,2,4]triazole and selective anti-proliferative activity of three isomeric triazolotriazoles," Acta Crystallographica Section C Structural Chemistry, vol. 75, pp. 1398-1404, 2019.

[3] Z. Jiang, J. Gu, C. Wang, S. Wang, N. Liu, Y. Jiang, G. Dong, Y. Wang, Y. Liu, J. Yao, Z. Miao, W. Zhang, C. Sheng, "Design, synthesis and antifungal activity of novel triazole derivatives containing substituted 1,2,3-triazole-piperdine side chains," European Journal of Medicinal Chemistry, vol. 82, pp. 490-497, 2014.

[4] M. M. Slaihim, F. S. R. Al-Suede, M. Khairuddean, M. B. Khadeer Ahamed, A. M. Shah Abdul Majid, "Synthesis, characterization of new derivatives with mono ring system of 1,2,4-triazole scaffold, and their anticancer activities," Journal of Molecular Structure, vol. 1196, pp. 78-87, 2019.

[5] M. A. A. Mohamed, O. A. Abd Allah, A. A. Bekhit, A. M. Kadry, A M. M. El-Saghier, "Synthesis and antidiabetic activity of novel triazole derivatives containing amino acids," J. Heterocyclic Chem., pp. 1-14, 2020.

[6] Y. El Bakri, Y. El Aoufir, H. Bourazmi, A. Harmaoui, J. Sebhaoui, A. Ben Ali, H. Oudda, A. Guenbour, M. Tabyaoui, Y. Ramli, E. M. Essassi, "The roles of 3, 4-diamino-5-phenyl-4H-1,2,4-triazole (TR) on the corrosion inhibition of steel in $\mathrm{HCl}$ media," J. Mater. Environ. Sci., vol. 8, pp. 33-43, 2017.

[7] R. Huisgen, "1,3-Dipolare cycloadditionen rückschau und ausblick," Angew. Chem., vol. 75, pp. 604-637, 1963.

[8] T. Curtius, "Ueber die Einwirkung von salpetriger Säure auf salzsauren Glycocolläther," Berichte Der Deutschen Chemischen Gesellschaft, vol. 16, pp. 2230-2231, 1883.

[9] E. Buchner, "Action of ethereal salts of diazoacetic acid on ethereal salts of unsaturated acids," Chem. Ber., vol. 21, pp. 2637-2647, 1888.

[10] A. Padwa and W. H. Pearson, Synthetic applications of 1,3-dipolar cycloaddition chemistry toward heterocycles and natural products. 2002, by John Wiley \& Sons, Inc., New York.

[11] R. Huisgen, G. Mloston, E. Langhals, "The first two-step 1,3-dipolar cycloadditions: non-stereospecificity," J. Am. Chem. Soc., vol. 108, pp. 6401-6402, 1986.

[12] A. Atmani, A. El Hallaoui, S. El Hajji, M. L. Roumestant, P. Viallefont, "From oxazolines to precursors of amino acids," Synth. Commun., vol. 21, pp. 2383-2390, 1991

[13] A. Elachqar, A. El Hallaoui, M. L. Roumestant, P. Viallefont "Synthesis of heterocyclic $\alpha$-amino phosphonic acids," Synth. Commun., vol. 24, pp. 1279-1286, 1994.

[14] Y. Aouine, H. Faraj, A. Alami, A. El Hallaoui, A. Elachqar, S. El Hajji, A. Kerbal, B. Labriti, J. Martinez, V. Rolland, "Synthesis of new triheterocyclic compounds, precursors of biheterocyclic amino acids," J. Mar. Chim. Heterocycl., vol. 7, pp. 44-49, 2008.

[15] Y. Aouine, H. Faraj, A. Alami, A. El Hallaoui, A. Elachqar, A. Kerbal, "Simple and efficient synthesis of racemic 2-(tertbutoxycarbonylamino)-2-methyl-3-(1H-1,2,4-triazol-1-yl)propanoic acid, a new derivative of $\beta$-(1,2,4-triazol-1-yl)alanine," Molecules, vol. 16, pp. 3380-3390, 2011.

[16] Y. Aouine, H. Faraj, A. Alami, A. El Hallaoui, A. Elachqar, S. El Hajji, B. Labriti, A. Kerbal, "Triheterocyclic compounds, oxazolinic precursors of biheterocyclic amino acids, Part II: phenothiazine derivatives and structural study of regioisomers through ${ }^{1} \mathrm{H}_{-}{ }^{15} \mathrm{~N} 2 \mathrm{D}$ NMR HMBC," J. Mar. Chim. Heterocycl., vol. pp. 39-47, 2014.
[17] Y. Aouine, A. Alami, A. El Hallaoui, " $N, N$-dibenzyl-1-(1-[(4-methyl2-phenyl-4,5-dihydrooxazol-4-yl)methyl)]-1H-1,2,3-triazol-4yl)methanamine," MolBank, 2014, M819, 2014.

[18] S. Hajib, A. Alami, H. Faraj, Y.Aouine, "4-[(3,5-Dimethyl-1Hpyrazol-1-yl)methyl]-4-methyl-2-phenyl-4,5-dihydrooxazole," Molbank, 2019, M1074, 2019.

[19] K. Dioukhane, A. Alami, Y. Aouine, M. El Omari, L. El Ammari, M. Saadi, A. Assani, R. Ouarsal, "Synthesis, crystal structure and IR spectrum studies of 2-(4-methyl-2-phenyl-4,5-dihydrooxazol-4ylmethyl)-isoindole-1,3-dione," Mediterr. J. Chem., vol. 9, pp. 116 124, 2019.

[20] S. Achamlale, A. Alami, Y. Aouine, "Structure assignment of $\mathrm{N}$ protected 2-(1H-1,2,3-triazol-1-yl)-glycine derivatives by chemical and spectroscopic methods," J. Mar. Chim. Heterocycl. vol. 18, pp. 61 69, 2019.

[21] S. A. K. Fall, K. Boukallaba, Y. Aouine, A. Alami, H. Faraj, "Synthesis and characterization of new 1,2,3-triazolyl $\alpha$-amino phophonate derivatives, through 1,3-dipolar cycloaddition reaction," J. Mar. Chim. Heterocycl., vol. 19, pp. 80-86, 2020

[22] S. A. K. Fall, S. Achamlale, Y. Aouine, A. Nakkabi, H. Faraj, A. Alami, "Diethyl [(4-\{(9H-carbazol-9-yl)methyl $\}-1 H$-1,2,3-triazol-1 yl)(benzamido)methyl]phosphonate," Molbank, 2020, M1167, 2020.

[23] S. Achamlale, A. Elachqar, A. El Hallaoui, S. El Hajji, A. Alami, M. L. Roumestant, P. Viallefont, "Synthesis of biheterocyclic $\alpha$-amino phosphonic acid derivatives," Phosphorus, Sulfur and Silicon, vol. 140 pp. 103-111, 1998

[24] F. Zaid, S. El Hajji, A. El Hallaoui, A. Elachqar, A. Alami, M. L. Roumestant, P. Viallefont, "Synthesis of heterocyclic $\alpha$-amino aldehyde and $\alpha$-amino acid analogues of histidine," Prep. Biochem And Biotechnol., vol. 28, pp. 155-165, 1998.

[25] G. I. Tsypin, T. N. Timofeeva, V. V. Mel'nikov, B. V. Gidaspov, "Structure and reactivity of aliphatic azido compounds. Isomeric composition of the products from cycloaddition of aliphatic azides to acetylene derivatives," Zh. Org. Khim., vol. 13, pp. 2275-2281, 1977.

[26] G. I. Tsypin, V. V. Mel'nikov, T. N. Timofeeva, B. V. Gidaspov, "Structure and reactivity of aliphatic azido compounds. Kinetics of the cycloaddition of alkylazides to acetylene derivatives," Zh. Org. Khim., vol. 13, pp. 2281-2283, 1977.

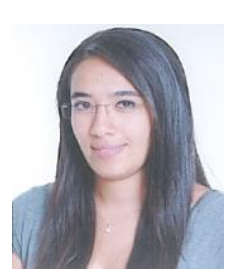

Hajib Sara was born in February 1990 in Fez, Morocco, where she completed her primary, secondary and university education.

The latter were capped respectively by obtaining a Bachelor's in chemical analysis techniques and quality control and a Master's degree in the chemistry of bioactive molecules at the Faculty of Sciences and Technologies of Fez in 2015.

Currently, she is pursuing for her Ph.D. degree at Sidi Mohammed Ben Abdellah University Faculty of Sciences Dhar El Mahraz, Fez, Morocco.

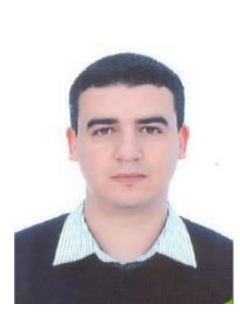

Kaskas Adil was born in 1989 in Fez, Morocco, where he completed her primary, secondary and university education. In 2017, he obtained his PhD in Chemistry, specialising in materials and process engineering at the Catalysis, Materials and Environment Laboratory of the Fez Higher School of Technology, Sidi Mohamed Ben Abdallah University. He is the author of several articles and scientific communications

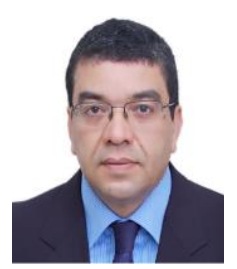

Alami Anouar was born in Fez, Morocco, in 1966 He studied Chemistry at Montpellier II University, France and he obtained his Ph.D. degree in 1991. He then joined the Department of Chemistry at the FSDM, USMBA Fez, Morocco in 1992. He prepared his state doctorate thesis degree in Organic Chemistry in 1997 at USMBA.

Among the responsibilities he assumed: Head of Department of Chemistry, elected for two terms 2013-2015 and 2016-2017 of the Council of FSDM, Chairman of the TRANSMEDITERRANEAN COLLOQUIUM ON HETEROCYCLIC CHEMISTRY, November 22-25, 2017, Fez, Morocco, http://tramech9.raidghost.com/, Responsible for the doctoral training "Bioactive Molecules, Health and Biotechnologies", 2014-2018, Director 
of the Laboratory of organic chemistry, 2014-2018, Coordinator of the Bachelor's degree program "Chemistry Sciences", FSDM, 2005-2012, Project Manager "President of the Coordination Commission with higher education, from the Board of the Academy of Fez-Boulemane Region, 2009-2012, Elected Member of the Council of USMBA, Fez, 2009-2011, Elected member of the Management Board USMBA, Fez 2011, Chairman of the International Symposium on heterocyclic chemistry, October 26-29, 2011. http://ishc2011.6te.net/Sitefr/index.html, Elected member of the college of the chemistry department, 2000-2012.

He strongly believes in the cognitive complementarity of science and in parallel to all his responsibilities, he had prepared a DEUG (2008) and a License (2010) in Private Law in French and a Master in Economics and Management (2013) at the Faculty of Economics, Law, and Social Sciences of Fez. Concerning the scientific research side. He had published more than 120 research articles indexed in several databases (Scopus, Web of science, Elsevier, Eric, IMIST...) till 2019.

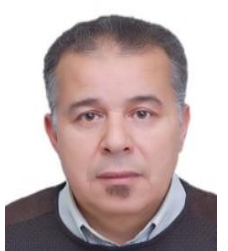

Faraj Hassane was born in Fez, Morocco, in 1963 He studied Chemistry at Montpellier II University, France and he obtained his Ph.D. degree in 1991. He then joined the department of chemistry at the Faculty of Sciences Dhar El Marhaz, Sidi Mohamed Ben Abdellah University (Fez, Morocco) in 1993.

His current research is focused on the synthesis and characterization of new heterocyclic $\alpha$-amino acids and their precursors and on the other hand on the study of their biological and electrochemical activities. He has taken part in conferences and communications in national and international congresses and has published the results of research $(+70$ publications and communications) in several international journals.

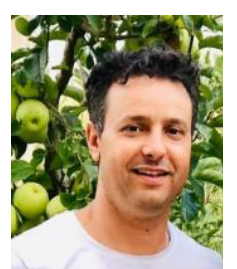

Aouine Younas was born in Ait-Seghrouchen of Taza Morocco, in 1979. He received his higher education diploma in Chemistry from the Sidi Mohamed Ben Abdellah University of Fez, Morocco, in 2003. He obtained his advanced degree (D.E.S.A) and Ph.D. degree in Organic and Heterocyclic Chemistry from the same university, in 2005 and 2015, respectively.

Since 2006, he has been working as a researcher in organic chemistry laboratory (LCO) with Professors a

Faculty of Sciences DM, University of Fez. In 2008, he joined the Ministry of Education as a professor of Physical Sciences and Chemistry in Imzouren High School, Al Hoceima in northern Morocco.

Since 2018, he joined the Department of Chemistry of the Ibn Zohr University, Agadir, as an assistant professor. His teaching has been devoted to organic and heterocyclic chemistry courses. His current research is focalized firstly on synthesis and characterization of new heterocyclic $\alpha$ amino acids and their precursors and on the other hand on the study of their biological and electrochemical activities. He has published the results of research (+70 publications and communications) in several international journals. Scopus Author ID: 35742904200. 